\title{
THE IMPACT OF MOTIVATION ON ORGANIZATIONAL \\ COMMITMENT: AN EMPIRICAL STUDY WITH KOSOVAR \\ EMPLOYEES
}

\section{Qëndrim BYTYQI}

University of Prishtina "Hasan Prishtina", Faculty of Economic, qendrimbytyqi077@gmail.com.

Article history:
Submission 10 September 2020
Revision 12 November 2020
Accepted 17 December 2020
Available online 31 December 2020

\section{Keywords:}

Motivation,

Organizational Commitment, Influence.

\begin{abstract}
A b s t r a c t
Motivation and organizational commitment are determinant factors that directly influence in the success of the organization. Work motivation is the process that initiates and maintains goal-directed performance, commitment encourages employees to voluntarily engage in the organization and have an intention to be member of organization for long term. This study investigates the relationship between motivation and organizational commitment. An online survey was conducted with 207 participants across Kosovo. The results of regression analysis shows that motivation has a significant effect in organizational commitment. The model summary shows that work motivation explains $36 \%$ of change in organizational commitment. The coefficient of work motivation shows that work motivation has a strong and positive effect on organizational commitment. Positive and strong correlation is found between work motivation (WM) and organizational commitment (OC). As much the employees are motivated that means they automatically will increase the job performance.
\end{abstract}

\section{Introduction}

Recent research in organizational behaviour has paid attention to the concepts that represent a departure from the traditional approach of studying work place behaviour. Work motivation has emerged as one of the important organization behavior that affects performance at work (Darolia \& Darolia, 2010). Organizational commitment can be inferred from an individual's degree of association with an organization, as the individual is willing to dedicate significant time and effort to the organization without monetary purposes. Affective commitment is an individuals' emotional or psychological attachment to, identification with, and participation in the organization (Bang et al, 2012). Organizational commitment and intrinsic motivation are important constructs in the human resources (HR) and organization behavior (OB) field. Both constructs share the personal characteristics and contextual characteristics for their antecedents. Moreover, they are two of the most frequently used variables for satisfaction, performance, change, and innovation and creativity. Although the consequences of organizational commitment and intrinsic motivation are not in the scope of this study, they ultimately influence employee job/career satisfaction and turnover, organizational performance, and employee creativity and innovation (Joo \& Lim, 2009). Work motivation is the process that initiates and maintains goal-directed performance. Motivation prevents or nudges us to convert intent into action. It also controls our decisions to persist at a specific work goal in the face of distractions and the press of other priorities. (Clar, 2003)

The purpose of this paper is to identify the factors that effects employee motivation and examining the relationship between motivation and organizational commitment.

\section{Literature Review}

\subsection{Motivation}

The topic of employee motivation plays a central role in the field of management, both practically and theoretically (Steers et al, 2004). Within the field of work motivation, as in the broader field of motivated or regulated behavior, much of the work falls within the cognitive tradition that evolved out of the work (Gagne \& Deci, 2005). The question about employee motivation has played a central role in management practice and theory since 20th century (Toode et al, 2011). Several definitions of motivation are 
available in the literature. Robbins \& Judge (2017) define motivation as the processes that account for an individual's intensity, direction, and persistence of effort toward attaining a goal. Yusof et al, (2013) explained motivation as the willingness of an individual to do something and conditioned by actions to satisfy needs. Sherif et al, (2014) define motivation as the strength of the people to make them able to choose specific work, to stay and work hard in the given position. Motivation encourages employees internally towards the actions which help them to achieve the goals or specific task which is assigned to him (Sohail et al, 2014). Motivation is defined as the forces, drives, needs, tension states, or other mechanisms that starts and maintain voluntary activity towards the achievement of personal goals (E.E \& Abraham, 2013) Motivation raises question on why people behave in the way they do it (Tella, 2007). Motivated people are those who have made a conscious decision to try considerably to achieve something they appreciate (Ismajli et al, 2015).

\subsection{Motivation Theories}

There are many different theories that try and help explain motivation. Some of them are: Maslow's Hierarchy of Needs, Herzberg's Two-Factor, Theory, Theory X \& Y etc.

\subsubsection{Maslow's Hierarchy of Needs}

In 1954, Maslow first published Motivation and Personality, which introduced his theory about how people satisfy various personal needs in the context of their work. He postulated, based on his observations as a humanistic psychologist, that there is a general pattern of needs recognition and satisfaction that people follow in generally the same sequence (Gawel, 1997). Maslow proposed that if people grew up in an environment in which their needs are not meet, they would be unlikely to function healthy, well-adjusted individual (Kaur, 2013). Maslow refused to believe that behavior was predetermined by the environment or subconscious, but he believed it was the consequence of human choices (Wilson \& Madsen, 2006). Maslow expressed the importance of elements such as job and play interaction, the discipline of hard work, creativity, and freedom of one's opinion (Shoura \& Singh, 1999). The theory has influenced the writings of many prominent authors in the field of management and organizational behavior (Wahba \& Bridwell, 1976). Maslow's Hierarchy of Needs is often used as an example of motivational theory in both practitioner and scholarly journals, yet considerable motivational research is being conducted that is not widely known, nor applied in practical settings (Kroth, 2007).

\subsubsection{Herzberg's Two-Factor Theory}

Frederick Herzberg in a bid to understand question and the issue of employee satisfaction and motivation in the 1950s and 60s set out to determine the effect of attitude on motivation by asking people to describe situations where they felt really good and really bad about their jobs (Dartey-Baah \& Amoako, 2011). Herzberg's influential need theory of the 1960's, the Two-Factor Theory, suggests that humans have two different sets of needs and that the different elements of the work situation satisfies or dissatisfies these needs (Lundberg et al, 2009). Herzberg made a theoretical departure from the traditional continuum concept by suggesting that job satisfaction was hypothesized to operate on a continuum which ranged from high to no job satisfaction-while job dissatisfaction operated on another continuum which ranged from no to high job dissatisfaction (Maidani, 1991).

\subsubsection{Theory $\mathrm{X}$ and $\mathrm{Y}$}

The 'Theory X' management assumes employees are inherently lazy and will avoid work if they can and that they inherently dislike work, theory $\mathrm{Y}$ is a participative style of management which assumes that people will exercise self-direction and selfcontrol in achieving the organizational goals and objectives (Hattangadi, 2015). Theory X and Y created by McGregor has been a valid basic principle from which to develop positive management style and techniques. McGregor's ideas suggest that there are two fundamental approaches to managing people. Several managers influenced by theory $\mathrm{x}$, and generally get poor results. On the other hand, liberal managers use theory $y$, which produces better performance and results, and allows people to grow and develop (Mohamed \& Nor, 2013). Theory X managers emphasize the chain of command, reward-or-punishment motivational techniques, and close supervision of subordinate behavior along rigidly defined behavioral parameters, Theory Y managers attempt to structure the work environment so that employee goals coincide with organizational goals, resulting presumably in greater creativity and productivity (Aydin, 2012).

\subsection{Types of Motivation}

Vallerand \& O'Connor, (1989) mentioned four types of motivation; Intrinsic motivation, self-determined extrinsic, nonself-determined extrinsic, and amotivation which are assumed to have a number of consequences for adaptation and well-being.

\subsubsection{Intrinsic Motivation}

Intrinsic motivation is a type of motivation based in people's natural interest in various activities that provide novelty and challenge. Intrinsically motivated behaviors do not require external rewards; rather, they are an expression of a person's sense of who they are, of what interests them. Intrinsically motivated behaviors have what is referred to in attribution theory as an internal perceived locus of causality; people experience the causes of their intrinsically motivated behaviors to be internal to themselves (Deci \& Ryan, 2009). In general, intrinsic motivation (IM) refers to engaging in an activity purely for the pleasure and 
satisfaction derived from doing the activity (Pelletier, etj., 1995). According to the theory, intrinsic motivation is based in the organismic needs for competence and self-determination (Reeve \& L.Deci, 1996)

\subsubsection{Self-Determined Motivation}

Self-determination theory is a prominent framework used to understand the antecedents and outcomes of PA-related. SDT allows for exploration of not only the amount of motivation towards PE, but also the extent to which motivation is selfdetermined in nature. Motivation can be experienced at both the global (i.e., across different life contexts) and situational levels. While global self-determination impacts motivation, we were particularly interested in how situational motivation (specific to a PE lesson) and features of the class environment influenced PA levels. (Lonsdale et al, 2009).

\subsubsection{Non-Self-Determined Extrinsic Motivation}

In the field of organizational behavior, researchers in the tradition of SDT argue outspokenly for the difference between intrinsic and extrinsic motivation for two reasons. First, when people are intrinsically motivated, "the correlates and consequences are more positive in terms of the quality of their behavior as well as their health and well-being". Second, extrinsic motivation is negatively related to intrinsic motivation . Therefore, according to SDT, an incentive that actually strengthens extrinsic motivation will, at the same time, undermine intrinsic motivation. Furthermore, given how the two types of motivation are defined, it is difficult to explain how and why intrinsic and extrinsic motivation should be positively related. The actions of performing an activity to experience the pleasure and satisfaction inherent in that activity and performing the same activity to procure positive consequences or avoid negative consequences are logically incompatible because this creates a cognitive challenge, and individuals usually concentrate on the more salient cue when acting (Kuvaas et al, 2017).

\subsubsection{Amotivation}

A last concept posited by self-determination theory is amotivation. Amotivation pertains to the lack of intentionalityand therefore refers to the relative absence of motivation (neither intrinsic nor extrinsic). Amotivated individuals experience feelings of incompetence and expectancies of uncontrollability (Guay, et al, 2015). Amotivation is a state of lacking any intention to engage in a behavior and is a completely non-self-determined form of regulation. External regulation involves engaging in a behavior only in order to satisfy external pressures or to achieve externally imposed rewards. Introjected regulation involves the internalization of external controls, which are then applied through self-imposed pressures in order to avoid guilt or to maintain self-esteem. Identification involves a conscious acceptance of the behavior as being important in order to achieve personally valued outcomes. Integrated regulation concerns the assimilation of identified regulation so that engaging in the behavior is fully congruent with one's sense of self. Intrinsic regulation involves taking part in an activity for the enjoyment and satisfaction inherent in engaging in the behavior itself (Markland \& Tobin, 2004).

\subsection{Organizational Commitment}

Organizational commitment is defined as a psychological state that binds the individual to the organization and is a three dimensions concept. First, affective commitment refers to the employee's emotional attachment to, identification with, and involvement in the organization. Second continuance commitment refers to an awareness of the costs associated with leaving the organization. Third, normative commitment reflects a feeling of obligation to continue employment (Castaing, 2006). Organizational commitment and job involvement have been major themes in the organizational literature, especially with regard to the prediction of organizational outcomes, such as turnover (Huselid \& Day, 1991). Cohen (2007) argue that concept of commitment represents a component of attitudinal commitment because he emphasized the awareness of the costs associated with leaving the organization. Affective Commitment reflects commitment based on emotional ties the employee develops with the organization primarily via positive work experiences (Jaros, 2007). Commitment represents something beyond more passive loyalty to an organization (Mowday, Steers, \& Porter, 1979). The attitude theorists view commitment as something of a 'black box', the contents of which are determined by a range of organizational and individual factors such as personal characteristics, role-related features, structural characteristics and work experiences (Oliver, 1990). Indeed, majority organizational commitment studies have been concerned on compensated employee rather than focused on nonprofit worker (Rahmawati et al, 2015).

\subsection{Relationship Between Motivation And Organizational Commitment}

The different authors in their previous paper have found that exist an important relationship between motivation and organizational commitment: Pitaloka \& Sofia (2014) found that Organization commitment significantly affect organization behavior of internal auditor. Commitment encourages employees to voluntarily engage in the organization and have an intention to be member of organization for long term. This can encourage the emergence of OCB behavior-organization oriented. With the commitment, 
employees being bound and loyal to the organization. Joo \& Lim (2009) found that when employees perceived that an organization provided a better organizational learning culture, they were more likely to realize job complexity, which in turn affected organizational commitment. Altindis (2011) in his finding found that the results indicated that intrinsic motivation of health professionals was explained mostly by affective and normative commitment. Also affective and normative commitment impact on intrinsic motivation was more than continuance commitment.

The most effective factor on extrinsic motivation was normative commitment. Continuance commitment had effect on extrinsic motivation less than normative commitment. Also it was seen that the affective commitment had the lowest effect on external motivation. Al-Madi et al, (2017) after statistical analyses found that the majority of employees choose "Tactful discipline" as their best source of motivation with (4.0103) as a mean value, they feel a nice treatment and behavior from their colleagues and they consider that as a big motivation for them. The Second preferred factor was "Supervisor's help with personal problems" with (3.1134) as a mean value, which is indicate to the importance of strong relationship between employees for participants and organizational commitment. Manzoor (2010) found that An internally satisfied, delighted and motivated worker or employee is actually a productive employee in an organization which contributes in efficiency and effectiveness of organization which leads to maximization of profits. Rahim \& Jam'an (2018) after statistical analyses founds that motivation has a positive and significant effect on employee performance through media and organizational commitment variables with a value of $p=0.00<$ 0.05 and a coefficient of 0.453 . It coefficient value shows that the better the organizational commitment of an employee, the motivation will also increase, so if employees' motivation increases it will affect the performance of the employee. If the employees' performance increases then it will have impact on overall performance of the organization.

\section{Methodology}

\subsection{Sampling Procedure}

In order to gather data, we have conducted an online survey with employees from Kosovo. A questionnaire was developed for this purpose. 207 surveys were found valuable for analysis purposes. $58 \%$ of the participants were male and $42 \%$ female. $59,9 \%$ of the participants belonged to the 20-29 age interval. $49,3 \%$ have a bachelor's degree. $60,4 \%$ live in urban area, 59,4\% are single, $42 \%$ have a $301-600$-euro income level. $71 \%$ work in private sector and $55,6 \%$ have $0-5$ years job experience.

\subsection{Measures}

Work Motivation was measured using 13 items adopted from William (2010). Sample items include " My company provide fair promotion opportunities, Promotion should be based on performance, My job is beneficial to my career. Using a fivepoint Likert scale ranging from 1 for 'strongly disagree' to 5 for 'strongly agree', participants were asked to assess each item.

Organizational Commitment was measured using 5 items adopted from Leisink \& Steijn (2015), saample items include " I do not really feel as if this department/unit's problems are my own, I feel emotionally attached to this department/unit, This department/unit has a great deal of personal meaning for me. Using a five-point Likert scale ranging from 1 for 'strongly disagree' to 5 for 'strongly agree', participants were asked to assess each item.

\section{Findings and Results}

Before proceeding with hypothesis testing, we have firstly conducted an Exploratory Factor Analysis (EFA), since the questionnaire was translated into a different language. Table 2 reports the results of EFA. As it was expected, two factors were revealed at the end of the EFA. KMO value $(\mathrm{KMO}=, 907)$ suggested that our data are very suitable to perform EFA. The value of total explained variance was 59,635 and this is beyond the accepted threshold ,50. Nonetheless, some items from Work Motivation scale and one item from Organizational Commitment scale were removed due to low weights. The first factor includes the items of work motivation; therefore, this factor is named as Work Motivation (WM). The second factor includes the items of organizational commitment, hence, labelled as Organizational Commitment (OC). After EFA, we performed reliability analysis for both factors. The Cronbach's Alpha coefficient for Work Motivation (WM) is ,912 and this value shows that this scale is very reliable. However, the Cronbach's Alpha coefficient for Organizational Commitment (OC) was under ,70 for four items. We deleted the OC1 item from the scale, and then the scale's reliability increased to, 795 . This value shows that the scale of OC is also reliable. The overall Cronbach's Alpha coefficient for 12 items is, 917 .

Table 4 reports the means and standard deviations, and correlations among all variables included in the survey. Positive and strong correlation $(\mathrm{r}=.599, \mathrm{p}<.01)$ is found between work motivation (WM) and organizational commitment (OC). WM is positively related to income $(r=.239, \mathrm{p}<.01)$. OC is positively associated with age $(r=.160, \mathrm{p}<.05)$, income $(r=.148, \mathrm{p}<.05)$ and job tenure $(\mathrm{r}=.169, \mathrm{p}<.05)$, and negatively with sector $(\mathrm{r}=-.142$, $\mathrm{p}<.05)$. 
Table 1. Sample statistics $(n=207)$

\begin{tabular}{|c|c|c|c|}
\hline Variable & & Frequency & Percent \\
\hline \multirow[t]{2}{*}{ Gender } & Male & 120 & 58.0 \\
\hline & Female & 87 & 42.0 \\
\hline \multirow[t]{5}{*}{ Age } & $20-29$ & 124 & 59.9 \\
\hline & $30-39$ & 52 & 25.1 \\
\hline & $40-49$ & 21 & 10.1 \\
\hline & $50-59$ & 7 & 3.4 \\
\hline & $60+$ & 3 & 1.4 \\
\hline \multirow[t]{4}{*}{ Education } & Primary school & 5 & 2.4 \\
\hline & High school & 37 & 17.9 \\
\hline & Bachelor & 102 & 49.3 \\
\hline & Master \& PhD & 63 & 30.4 \\
\hline \multirow[t]{2}{*}{ Settlement } & Urban & 125 & 60.4 \\
\hline & Rural & 82 & 39.6 \\
\hline \multirow[t]{3}{*}{ Status } & Single & 123 & 59.4 \\
\hline & Married & 76 & 36.7 \\
\hline & Divorced \& Widow & 8 & 3.9 \\
\hline \multirow[t]{5}{*}{ Income } & 0-300 euro & 70 & 33.8 \\
\hline & $301-600$ euro & 87 & 42.0 \\
\hline & $601-900$ euro & 23 & 11.1 \\
\hline & 901-1200 euro & 17 & 8.2 \\
\hline & Over 1200 euro & 10 & 4.8 \\
\hline \multirow[t]{2}{*}{ Sector } & Public & 60 & 29.0 \\
\hline & Private & 147 & 71.0 \\
\hline \multirow[t]{4}{*}{ Job tenure } & $0-5$ years & 115 & 55.6 \\
\hline & $6-10$ years & 54 & 26.1 \\
\hline & $11-15$ years & 20 & 9.7 \\
\hline & More than 15 years & 18 & 8.7 \\
\hline
\end{tabular}

Table 2 Exploratory Factor Analysis (EA)

\begin{tabular}{|c|c|c|c|c|}
\hline & \multicolumn{3}{|c|}{ Component } & \multirow[t]{2}{*}{ Total Explained Variance } \\
\hline & WM & $\mathrm{OC}$ & KMO & \\
\hline WM6 & .809 & & .907 & 59.635 \\
\hline WM9 & .802 & & & \\
\hline WM4 & .786 & & & \\
\hline WM1 & .781 & & & \\
\hline WM12 & .775 & & & \\
\hline WM10 & .756 & & & \\
\hline WM13 & .715 & & & \\
\hline WM5 & .702 & & & \\
\hline WM3 & .501 & & & \\
\hline OC3 & & .778 & & \\
\hline OC2 & & .778 & & \\
\hline OC5 & & .600 & & \\
\hline OC1 & & .526 & & \\
\hline
\end{tabular}

Extraction Method: Principal Component Analysis. Rotation Method: Varimax with Kaiser Normalization.

a. Rotation converged in 3 iterations.

Table 3. Reliability Analysis

\begin{tabular}{lcc}
\hline Variable & Cronbach's Alpha & N of Items \\
\hline WM & .912 & 9 \\
OC & .795 & 3 \\
Total reliability & .917 & 12 \\
\hline
\end{tabular}


Finally, in Table 5, we have reported the results of regression analysis to test the effect of work motivation on organizational commitment. The model summary shows that work motivation explains $36 \%$ of change in organizational commitment. The coefficient of work motivation $(\beta=.572, \mathrm{p}<.000)$ shows that work motivation has a strong and positive effect on organizational commitment. This result shows support for our hypothesis.

\section{Conclusion and Discussion}

This study examined the relationship between motivation and dedication to the organization. The findings showed that motivation has a positive influence on organizational commitment as well as regression analysis showed that motivation has a positive effect on overall organizational involvement. Employees that are well motivated are directly involved in the success of the organization. Motivation and organization commitmment goes together so an well motivation means automatically well organizational commitment. Kim, (2006) found that exist an important relationship between motivation and organiztional commitmment especially an important relationship between job satisfaction and orgnizational commitment. Austen \& Zacny, (2015) also found an possitive relationship between motivation and organizational commitment. Ates \& Buluc, (2017) found that and intrinsic motivation is the best indicator of motivation.

Table 4. Descriptive Statistics and Correlation Analysis

\begin{tabular}{|c|c|c|c|c|c|c|c|c|c|c|c|c|}
\hline & Mean & St. Dev. & 1 & 2 & 3 & 4 & 5 & 6 & 7 & 8 & 9 & 10 \\
\hline $1 \mathrm{WM}$ & 3.405 & .882 & 1 & & & & & & & & & \\
\hline 3 gender & 1.42 & .495 & -.110 & .008 & 1 & & & & & & & \\
\hline 4 age & 1.61 & .906 & -.094 & $.160^{*}$ & .007 & 1 & & & & & & \\
\hline 6 settlement & 1.40 & .490 & -.047 & -.044 & -.049 & .029 & $-.213^{* *}$ & 1 & & & & \\
\hline 7 status & 1.45 & .605 & -.066 & .075 & .057 & $.526^{* *}$ & $-.204^{* *}$ & -.037 & 1 & & & \\
\hline 8 income & 2.08 & 1.101 & $.239^{* *}$ & $.148^{*}$ & -.099 & $.344^{* *}$ & .062 & -.043 & $.228^{* * *}$ & 1 & & \\
\hline
\end{tabular}

**. Correlation is significant at the 0.01 level (2-tailed). *. Correlation is significant at the 0.05 level (2-tailed).

Table 5. Linear Regression Results

\begin{tabular}{ccccccccc}
\hline $\begin{array}{c}\text { Dependent } \\
\text { Variable }\end{array}$ & $\begin{array}{c}\text { Independent } \\
\text { Variables }\end{array}$ & $\boldsymbol{\beta}$ & $\mathbf{t}$ & $\mathbf{p}$ & $\mathbf{F}$ & Model (p) & $\mathbf{R}$ & $\mathbf{R}^{2}$ \\
\hline OC & Constant & 1.701 & 9.065 & .000 & 114.808 & .000 & .599 & .359 \\
& WM & .572 & 10.715 & .000 & & & \\
\hline
\end{tabular}

\subsection{Contribution}

This current study demonstrates the impact of motivation on participation in the organization. The morale of the employee must be taken into account by all the company if they want to accomplish their goals as the findings of this study indicates that the more motivated the workers are, they are more involved in the workplace and that directly implies the success of the organizations. Kosovar companies must have in consideration the employee motivation othervise they can lost them and the cost for the company will be high because at least are the employess who makes alive a company.

\subsection{Limitations and Suggestions for Future Research}

This research does have some limitations. First, the online survey was completed by research participants, and data collection is limited to the people who could reach the link. The questionnaire was too long and that may have caused a lot of people to start and leave the questionnaire without finishing. Second, this study's 
findings are limited to only the sample. Although the survey was attended by different people across Kosovo, making a generalisation is not enough. The results may not represent all of Kosovo's workforce population. Future studies will also concentrate on discrepancies between different employee hierarchies in motivation and organizational engagement, in this type next studies may find other findings that will support other study.

\section{References}

1. Al-Madi, F. N., Assal, H., Shrafat, F., \& Zeglat, D. (2017). The Impact of Employee Motivation on Organizational Commitment. European Journal of Business and Management, 9(15), 134-145.

2. Altindis, S. (2011). Job motivation and organizational commitment among the health professionals: A questionnaire survey. African Journal of Business Management, 5, 8601-8609.

3. Ates, O. T., \& Buluc, B. (2017). The Relationship between the Emotional Intelligence, Motivation and Organizational Commitment of Primary School Teachers. Middle Eastern \& African Journal of Educational Research(17).

4. Austen, A., \& Zacny, B. (2015). The role of Public Service Motivation and Organizational Culture for Organizational Commitment. Management, 19(2), 2134.

5. Aydin, O. T. (2012). The Impact of Theory X, Theory Y and Theory $Z$ on Research Performance: An Empirical Study from A Turkish University. International Journal of Advances in Management and Economics, 1(5), 2430 .

6. Bang, H., Ross, S., \& Thomas G. Reio, J. (2012). From motivation to organizational commitment of volunteers in non-profit sport organizations The role of job satisfaction. Journal of Management Development, 32(1), $96-112$.

7. C. R. Darolia, P. K., \& Darolia, S. (2010). Perceived Organizational Support, Work Motivation, and Organizational Commitment as determinants of Job Performance. Journal of the Indian Academy of Applied Psychology, 36(1), 69-78.

8. Castaing, S. (2006). The Effects of Psychological Contract Fulfilment and Public Service Motivation on Organizational Commitment in the French Civil Service. Public Policy and Administration, 21(1), 84-98.

9. Clar, R. E. (2003). Fostering the Work Motivation of Individuals and Teams. Performance Improvement, 42(3), 21-29.
10. Cohen, A. (2007). Commitment before and after: An evaluation and reconceptualization of organizational commitment. Human Resource Management Review, 336-354.

11. Dartey-Baah, K., \& Amoako, G. K. (2011). Application of Frederick Herzberg's Two-Factor theory in assessing and understanding employee motivation at work: a Ghanaian Perspective. European Journal of Business and Management, 3(9), 1-8.

12. Deci, E. L., \& Ryan, R. M. (2009). The Corsini Encyclopedia of Psychology.

13. E.E, A., \& Abraham, N. M. (2013). Achievement of Abraham Maslow's Needs Hierarchy Theory among Teachers: Implications for Human Resource Management in The Secondary School System in Rivers State. Journal of Curriculum and Teaching, 2, 140-144.

14. Gagne, M., \& Deci, E. L. (2005). Self-determination theory and work motivation. Journal of Organizational Behavior, 26, 331-362.

15. Gawel, J. E. (1997, November). Herzber Herzberg's Theor s Theory of Motiv y of Motivation and Maslow' ation and Maslow's Hierarchy of Needs. Practical Assessment,Research \& Evaluation, 5, pp. 1-3.

16. Guay, F., Mageau, G. A., \& Vallerand, R. J. (2015, March). On the Hierarchical Structure of SelfDetermined Motivation: A Test of Top-Down, BottomUp, Reciprocal, and Horizontal Effects. Hierarchy Of Self-Determined Motivation, pp. 992-1003.

17. Hattangadi, V. (2015). Theory X \& Theory Y. International Journal of Recent Research Aspects, 2(4), 20-21.

18. Huselid, M. A., \& Day, N. E. (1991). Organizational Commitment, Job Involvement, and Turnover: A Substantive and Methodological Analysis. Journal of Applied Psychology, 76(3), 380-391.

19. Ismajli, N., Zekiri, J., Qosja, E., \& Krasniqi, I. (2015). The Importance of Motivation Factors on Employee Performance in Kosovo Municipalities. Journal of Political Sciences \& Public Affairs, 3(2), 2-6.

20. Jaros, S. (2007). Meyer and Allen Model of Organizational Commitment: Measurement Issues. Journal of Organizational Behavior, 6(4), 8- 25.

21. Joo, B.-K. (., \& Lim, T. (2009). The Effects of Organizational Learning Culture, Perceived Job Complexity, and Proactive Personality on Organizational Commitment and Intrinsic Motivation. Journal of Leadership \& Organizational Studies, 16(1), 48-60.

22. Joo, B.-K. (., \& Lim, T. (2009). The Effects of Organizational Learning Culture, Perceived Job 
Complexity, and Proactive Personality on Organizational Commitment and Intrinsic Motivation. Journal of Leadership \& Organizational Studies, 16(1), 48-60.

23. Kaur, A. (2013). Maslow's Need Hierarchy Theory: Applications and Criticisms. Global Journal of Management and Business Studies, 3, 1061-1064.

24. Kim, S. (2006). Public service motivation and organizational citizenship behavior in Korea. International Journal of Manpower, 27(8), 722-740.

25. Kroth, M. (2007). Maslow - Move Aside! A Heuristical Motivation Model for Leaders in Career and Technical Education. Journal of Stem Teacher Education, 44(2), 536.

26. Kuvaas, B., Buch, R., Weibel, A., Dysvik, A., \& Nerstad, C. G. (2017). Do intrinsic and extrinsic motivation relate differently to employee outcomes? Journal of Economic Psychology, 244-258.

27. Leisink, P., \& Steijn, B. (2015). Public service motivation and job performance of public sector employees in the Netherlands. International Review of Administrative Sciences, 36-52.

28. Lonsdale, C., Sabiston, C. M., Raedeke, T. D., Ha, A. S., \& Sum, R. K. (2009). Self-determined motivation and students' physical activity during structured physical education lessons and free choice periods. Preventive Medicine, 69-73.

29. Lundberg, C., Gudmundson, A., \& Andersson, T. D. (2009). Herzberg's Two-Factor Theory of work motivation tested empirically on seasonal workers in hospitality and tourism. Tourism Management, 890899.

30. Maidani, E. A. (1991). Comparative Study of Herzberg's Two-Factor Theory of Job Satisfaction Among Public and Private Sectors. Public Personnel Management, 20(4), 441- 448.

31. Manzoor, Q.-A. (2010). Impact of Employees Motivation on Organizational Effectiveness. European Journal of Business and Management, 3(3), 36-44.

32. Markland, D., \& Tobin, V. (2004). A Modification to the Behavioural Regulation in Exercise Questionnaire to Include an Assessment of Amotivation. Journal of Sport \& Exercise Psychology , 191-196.

33. Mohamed, R. K., \& Nor, D. C. (2013). The Relationship between McGregor's X-Y Theory Management Style and Fulfillment of Psychological Contract: A Literature Review. International Journal of Academic Research in Business and Social Sciences, 3(5), 715-720.
34. Mowday, R. T., Steers, R. M., \& Porter, L. W. (1979). The Measurement of Organizational Commitment. Journal of Vocational Behavior, 224-247.

35. Oliver, N. (1990). Rewards, investments, alternatives and organizational commitment: Empirical evidence and theoretical development. Journal of Occupational Psycbology, 19-31.

36. Pelletier, L. G., Fortier, M. S., Vallerand, R. J., Tuson, K. M., Briere, N. M., \& Blais, M. R. (1995). Toward a New Measure of Intrinsic Motivation, Extrinsic Motivation, and Amotivation in Sports: The Sport Motivation Scale (SMS). Journal of Sport \& Exercise Psychogy, 35-53 .

37. Pitaloka, E., \& Sofia, I. P. (2014). The Affect of Work Environment, Job Satisfaction, Organization Commitment On OCB of Intenal Auditors. International Journal of Business, Economics and Law, 5(2), 10-18.

38. Rahim, A. R., \& Jam'an, A. (2018). The Analysis of Influence of Motivatin and Organizational Commitment on Employees Performance on Telkom Kandatel Gorontalo Province. Problems and Perspectives in Management, 16(4), 429-443.

39. Rahmawati, Y., Abiddin, N. Z., \& Ro'is, I. (2015). Relationship Between Motivation and Organizational Commitment among Scout Volunteers in East Kalimantan. Journal of Social Science Studies, 2(1), 5163.

40. Reeve, J., \& L.Deci, E. (1996). Eclement of the Competitive Situation that affect Intrinsic Motivation. Society for Personality and Social Psychology, 22(1), 24-33.

41. Robbins, S. P., \& Judge, T. A. (2017). Organizational Behavior (17th Global Edition ed.). England: Pearson Education Limited.

42. Sherif, M. Z., Nimran, U., Prasetya, A., \& S.Sos. (2014). The Role of Motivation in Human Resources Management: The Importance of Motivation Factors among Future Business Professionals in Libya. Journal of Business and Management, 16(8), 27-36.

43. Shoura, M. M., \& Singh, A. (1999). Motivation Parameters For Engineering Managers Using Maslow's Theory. Journal of Management In Engineering, 44-55.

44. Sohail, A., Safdar, R., Saleem, S., Ansar, S., \& Azeem, M. (2014). Effect of Work Motivation and Organizational Commitment on Job Satisfaction: (A Case of Education Industry in Pakistan). Global Journal of Management and Business Research: A Administration and Management, 14(6), 2249-4588.

45. Steers, R. M., Mowday, R. T., \& Shapiro, D. L. (2004). Introduction to Special Topic Forum: The Future of 
Work Motivation Theory. Academy of Management Review, 29(3), 379-387.

46. Tella, A. (2007). The Impact of Motivation on Student's Academic Achievement and Learning Outcomes in Mathematics among Secondary School Students in Nigeria. Eurasia Journal of Mathematics, Science \& Technology Education, 3(2), 149-156.

47. Toode, K., Routasalo, P., \& Suominen, T. (2011). Work motivation of nurses: A literature review. International Journal of Nursing Studies, 48(2), 246-257.

48. Vallerand, R. J., \& O'Connor, B. P. (1989). Motivation In The Elderly: A Theoretical Framework And Some Promising Findings. Canadian Psychology, 538-550.

49. Wahba, M. A., \& Bridwell, L. G. (1976). Maslow Reconsidered: A Review of Research on the Need Hierarchy Theory. Organizational Behavior And Human Performance, 212-240.

50. William, A. N. (2010). Employee Motivation and Performance.

51. Wilson, I., \& Madsen, S. R. (2006). The Influence of Maslow Humanistic Views on an Employee's Motivation to Learn. Orem, Utah.

52. Yusof, W. F., Kian, T. S., \& Idris, M. T. (2013). Herzberg's Two Factors Theory on Work Motivation: Does Its Work For Todays Environment? Global Journal of Commerce \& Management Perspective, 2(5)(2319 7285), 18-22. 